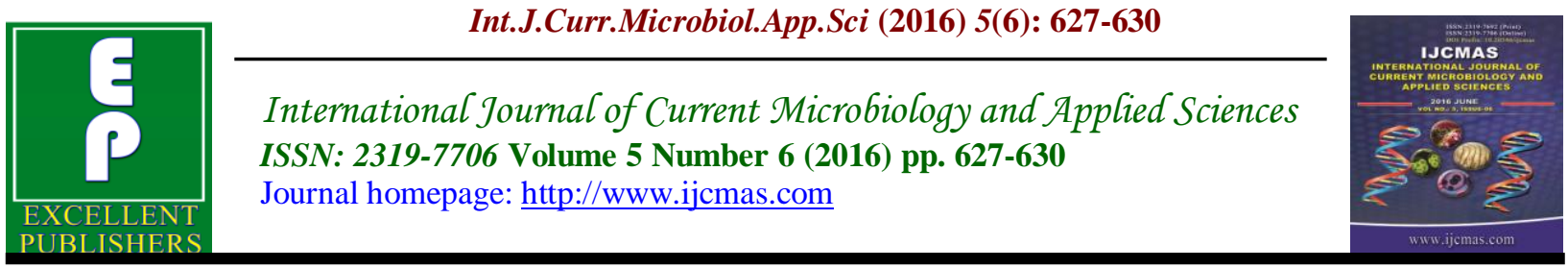

Case Study

http://dx.doi.org/10.20546/ijcmas.2016.506.068

\title{
Edwardsiella tarda: An Uncommon Causative Agent of Cellulitis
}

\author{
K.B. Jnaneshwara, Asha B. Patil*, Arti Kalkutkar, G. P. Aaftab Ahmed and S. Sheethal \\ Department of Microbiology, Karnataka Institute of Medical Sciences, Hubli, Karnataka, India \\ *Corresponding author
}

Keywords

Edwardsiella

Tarda,

Cellulitis.

Article Info

Accepted:

22 May 2016

Available Online:

10 June 2016
A B S T R A C T

Edwardsiella tarda is an uncommon causative agent of soft tissue infections. It is primarily associated with gastroenteritis. We report a case of cellulitis in a diabetic patient who was a regular fish eater. A high index of suspicion of this isolate in extraintestinal infections is indicated.

\section{Introduction}

Edwardsiella tarda is an opportunistic and rare pathogen in humans. (John, 2012) It is predominantly found in freshwater environments colonizing the guts of fish and in the intestinal tracts of reptiles, birds and mammals. (Golub et al., 2010)

It is primarily associated with gastrointestinal disease, although recent reports of extraintestinal disease are broadening the current understanding of the clinical spectrum of E.tarda. (Slaven et al., 2001) Here we report a case of a known diabetic who developed cellulitis due to infection by E. tarda.

\section{Case Report}

A 65 year old male was admitted to the surgical ward, Karnataka Institute of Medical Sciences, Hubli.
Patient gave a history of intense pain in his left foot and leg for 15 days which was severe and spontaneous in nature. $\mathrm{He}$ presented with purulent discharge, swelling of left foot with gangrenous changes in the second left toe. He did not give any history of trauma to the lower limb related to aquatic environment or otherwise, nor did he report any exposure to animals. He often ate sea food. He is a tailor by profession and a known case of diabetes mellitus for the past 5 years. Other than diabetes he was noton any other medication.

Preliminary blood investigations like complete hemogram, liver function tests, renal function test, lipid profile were within normal range. His glycemic index was under control. He tested nonreactive to HIV. Based on Doppler sonography, patient was diagnosed to have peripheral vascular 
disease involving dorsalispedis and tibial artery (which was previously not detected). A clinical diagnosis of peripheral vascular disease with cellulitis and gangrene of second left toe was made. The pus discharge was sent for microbiological examination. Patient was started on ceftriaxone and amikacin empirically and below knee amputation was done.

\section{Laboratory Investigations}

The pus sample was processed for culture and sensitivity as per standard protocol. After 24 hours of incubation, MacConkey plate showed pure growth of non lactose fermenting colonies. The isolate was motile Gram negative bacillus, catalase positive and oxidase negative.

Based on the biochemical reactions the isolate was identified as E.tarda. The isolate was sensitive to ampicillin, cefoxitin, ceftriaxone, cefoperazone, cefixime, cefepime, gentamicin, amikacin, pefloxacin, imipenem, while it showed resistance to cotrimoxazole, colistin and polymyxin B.

\section{Results and Discussion}

Human infections caused by pathogens transmitted from fish or the aquatic environment are quite common and depend on the season, patients' contact with fish and related environment, dietary habits and the immune system status of the exposed individual. The infection source may be fish kept both for food and as a hobby.

Edwardsiella tarda is a member of family Enterobacteriaceae and along with E.ictaluri and E.hoshinae, constitutes the genus Edwardsiella. It is the only species from the genus to cause significant disease in humans. It is known to colonize gastrointestinal tracts of reptiles, birds and mammals.
Human infections caused by E.tarda are considered rare and have only occasionally been described outside tropical or subtropical areas. This organism can result in manifestations ranging from an asymptomatic carrier state or mild gastroenteritis to typhoid-like illness and colitis or even extraintestinal infections. Such instances are very often associated with immune-compromised states.

E. tarda is known to cause potentially fatal infections if left untreated. E.tarda associated sepsis, has a mortality rate that approaches $50 \%$.

The isolate is reported to cause a diverse array of infections like tuboovarian abscess, bilateral salpingitis, bloodstream infections, neonatal sepsis and cholangitis.

An immunodeficient individual with sepsis and hepatic abscesses infected as a result of a hobby (fishing) has been reported.

Review of eleven cases by Slaven EM et al., revealed five cases associated with wound infections, 3 of which occurred in marine environment; an arm laceration after a fall in brackish water, a fall in a canal and a puncture wound to a foot that happened after the patient stepped on fish bones.

Although wound infections have been reported, the only reported patient with a necrotic deep soft tissue infection (myonecrosis) caused by E.tarda was a 67year old man with cirrhosis and hepatocellular cancer.

Our case had cellulitis, there was no myonecrosis. The gangrenous changes in the second left toe was secondary to peripheral vascular disease. It is pertinent to note that our patient sought medical attention quite early in the infection and the course and 
progress if left untreated is at best speculative.

A case similar to ours, a 52 year old diabetic male with cellulitis of the left foot has been documented. Five days before admission he had been fishing and had stepped on a catfish sustaining a penetrating wound. (Clarridge et al., 1980)

Risk factors for E.tarda infections include exposure to aquatic environments or exposure to animals (e.g., reptiles or amphibians), pre-existing liver disease, conditions leading to iron overload, dietary habits (e.g., ingestion of raw fish), extremes of age and a deficient immune system.

In our case there were no gastrointestinal manifestations. Apart from his dietary habits and diabetes, no other risk factors were present.

Contact with marine environment, eating raw fish, immersion in a contaminated body of water, and penetrating trauma from a colonized vector are among the described modes of transmission. (Janda et al., 1993)

The source and mode of infection in our case could not be ascertained conclusively. Although the patient did not remember any trauma to the limb, in view of the diabetes and the associated neuropathy it is likely that a minor trauma might have gone unnoticed. The mode of transmission is therefore presumably a minor trauma followed by contact with infected fish while handling them.

Increasing numbers of reports describe serious infections secondary to E.tarda alone, which provides evidence that this organism can cause significant morbidity and death. The authors also suggested that E.tarda is singularly capable of causing limb and life threatening infections.
In the laboratory, E.tarda closely resembles Salmonella biochemically, particularly in its ability to produce hydrogen sulphide on common laboratory media. This may lead to mis-identification. Indole production is a distinguishing feature of E.tarda. Although a rare cause of soft tissue infection, it is important to keep this isolate in mind and put up appropriate biochemical tests for identification.

E.tarda are is reported to be sensitive to most of the routinely used. However, resistance to colistin and polymyxin $\mathrm{B}$ and production of betalactamase has been documented which poses a therapeutic challenge. Our isolate was not a beta lactamse producer but was resistant to cotrimoxazole, colistin and polymyxin B.

In conclusion, although rare, E. tarda has been reported to cause a diverse array of extraintestinal infections. A high index of suspicion of this organism in cases other than gastroenteritis is therefore indicated. The possibility of this isolate as a potential causative agent of limb and life threatening infections needs to be studied.

\section{References}

John, A.M., Prakash, J.J., Simon, E.G., Thomas, N. 2012. Edwardsiella tarda sepsis with multiple liver abscesses in a patient with Cushing's syndrome. Indian J. Med. Microbiol., 30: 352-4.

Golub, V., Kim, A.C., Krol, V. 2010. Surgical wound infection, tuboovarian abscess, and sepsis caused by Edwardsiella tarda: case reports and literature review. Infect., 38(6): 487-9.

Slaven, E.M,. Lopez, F.A., Hart, S.M., Sanders, C.V. 2001. Myonecrosis Caused by Edwardsiella tarda: A Case Report and Case Series of 
Extraintestinal E.tarda Infections. Clin. Infect. Dis., 15: 32(10): 1430-3.

Novotny, L., Dvorska, L., Lorencova, A., Beran, V., Pavlik, I. 2004. Fish: a potential source of bacterial pathogens for human beings. Vet. Med- Czech, 49(9): 343-358.

Mowbray, E.E., Buck, G., Humbaugh, K.E.,

Marshall, G.S. 2003. Maternal Colonization and Neonatal Sepsis Caused by Edwardsiellatarda. Pediatrics, 111(3): e296-8.

Clarridge, J.E., Musher, D.M., Fainstein, V., Wallace, R.J. 1980. Extraintestinal Human Infection Caused by Edwardsiella tarda. J. Clin Microbiol., 11(5): 511-514.

Janda, J.M., Abbott, S.L., Kroske-Bystrom, S., Cheung, W.K., Powers, C., Kokka, R.P., et al. 2001. Pathogenic properties of Edwardsiella species. J. Clin. Microbiol., 29: 1997-2001.

Janda, J.M., Abbott, S.L. 1993. Infections associated with the genus Edwardsiella: the role of Edwardsiella tarda in human disease. Clin. Infect. Dis., 17: 742-748.

Nelson, J.J., Nelson, C.A,. Carter, J.E. 2009. Extraintestinal manifestations of Edwardsiella tarda infection: a 10year retrospective review. J. La State Med. Soc., 161: 103-106.

Reinhardt, J.F., Fowlston, S., Jones, J., George, W.L. 1985. Comparative In Vitro Activities of Selected Antimicrobiol Agents Against Edwardsiella tarda. Antimicrobial Agents and Chemotherapy, 27(6): 966967.

\section{How to cite this article:}

Jnyaneshwara, K.B., Asha B. Patil, ArtiKalkutkar, Aaftab Ahmed and Sheethal. 2016. Edwardsiella tarda: An Uncommon Causative Agent of Cellulitis. Int.J.Curr.Microbiol.App. Sci. 5(6): 627-630.

doi: http://dx.doi.org/10.20546/ijcmas.2016.506.068 